\title{
Natural Patterns and Magnetic and Mental Processes of Coronavirus Activation and Neutralization
}

\author{
Evgeny Bryndin \\ Research Department of Research Centre "NATURE INFORMATIC" of Technological Platform Future Medicine, Novosibirsk, Russia.
}

Corresponding Author: Evgeny Bryndin, Research Department of Research Centre "NATURE INFORMATIC" of Technological Platform Future Medicine, Novosibirsk, Russia.

Received date: November 29, 2021; Accepted date: January 03, 2022; Published date: January 10,2022

Citation: Evgeny Bryndin (2022). Natural Patterns and Magnetic and Mental Processes of Coronavirus Activation and Neutralization. J. Archives of Medical Case Reports and Case Study, 5(2); DOI:10.31579/2692-9392/087

Copyright: (C) 2022 Evgeny Bryndin, This is an open access article distributed under the Creative Commons Attribution License, which permits unrestricted use, distribution, and reproduction in any medium, provided the original work is properly cited.

\begin{abstract}
For twenty years, humanity has seen the third attempt at the transition of coronavirus to humans. The vaccine has been found, but coronavirus transitions will not stop even with the improvement of medicine. Nobel laureate in medicine Professor Luc Montagnier argues that vaccines may not live up to humanity's hopes of getting rid of COVID-19. Collective immunity for coronavirus has not been developed, repeated infections are more and more common, beds of seriously ill people are not empty, and mortality is running high, no one knows what will happen to all of us. In Israel, where vaccination has long been compulsory, and over $60 \%$ of the population, including underage children, have been vaccinated, the incidence is not just declining, but still breaking all records. So, the maximum number of cases here was revealed on September 1 - 16,629, which almost caught up with Russia (18,368 confirmed on the same September 1) with our percentage of vaccinated $26.1 \%$ of the number of citizens. At the end of September 2021, morbidity and mortality increase, because it is a system. Based on existing monthly pneumonia mortality statistics over the past 15 years, there are three waves each year. Since September 22, there has been a surge of pneumonia, ARI, and even non-communicable diseases. The second wave comes at the end of December - January, it is usually three times larger than the first. Then around March-April there is a third wave. These three waves exist steadily from year to year, their amplitudes can change, then one will be higher, then the other, they are not absolutely hard on schedule, but they are reproduced regularly in other countries. The first wave of the Spanish pandemic covered the world just at the end of September 1918. The coronavirus was the same. The first wave in America is September 2019, an unexplained surge of pneumonia with a rather high mortality rate, which was written off for smoking e-cigarettes and called "vape." Now they decided to watch the surviving tests of patients, and there - COVID-19. In Europe, it was the same.
\end{abstract}

Key words: coronavirus; pandemic; spiritual cleansing; pole change; magnetic therapy

\section{Introduction}

The outbreak of coronavirus occurred simultaneously and almost synchronously in different countries. And this corresponds to the classical ideas of virology. Three waves of coronavirus exist from year to year at intervals of three months - three months - three months. There is a natural mechanism that can control such waves. June 22 is the day of the summer solstice, December 22 is the day of the winter solstice, September 22 and March 22 are the days of the autumn and spring equinox, respectively. Increasing and decreasing morbidity in humans is always close to these astronomical points. Statistics on heart attacks and strokes, and it turned out that non-communicable diseases have the same rise in mortality on the same dates. For other bacteria, streptococci and staphylococci, in these numbers all microflora is activated, which causes the corresponding diseases.
Infections are usually transmitted under three conditions: a large dose of pathogen, quite close contact or epizootia - an outbreak of infection. Population density becomes additional stimuli for the high rate of infection. Viruses do not affect separately Chinese or representatives of other nations, viruses are apolitical and have no religion. They can adapt to any changes in the environment no worse than a person. The only thing to thank them for is the evolutionary perfection of the human immune system. For centuries, when any infection appeared, the human body produced antibodies and formed cellular immunity. When there are more than $30 \%$ of people with antibodies, we can say that the epidemic will end soon. Scientists have the opportunity to observe attempts by viruses to make a crossview transition thanks to laboratory tracking methods. 
The outbreak of epidemics is not an accident, but a combination of circumstances. And all of them are caused by changes in the environment. This is always a unique situation that occurs as a result of a change in the state of the environment, in which a person falls into new conditions of interaction with other species of animals. And today the anthropogenic impact on the environment has reached absolutely unmatched proportions compared to previous generations, in addition, man as a species is constantly growing.

At the beginning of the last century, the famous scientist Chizhevsky studied dark spots in the sun and revealed the amazing synchrony of solar energies and their influence on terrestrial biological processes. Viruses have receptors that are simultaneously activated during this period. Waves of infectious diseases flare up in different countries at the same time. Now we have $80 \%$ delta, and before that there was a gamma, and before that the British strain. Each of the strains gives way to a new mutation. The evolution of viruses occurs just inside the human body, its living reservoir.

The natural mechanism causes viruses to activate simultaneously and everywhere. In the spring of 2020, outbreaks of coronavirus were found on several warships in different parts of the world at once, and the ships were on the flight for a long time and the teams were isolated from everyone. Asynchronous incidence rises are caused by the influence of magnetic fields of natural origin.

Coronaviruses have been known since the $60 \mathrm{~s}$, there are several dozen of them, people are infected with them. Cases of COVID-19 disease are now recorded in all corners of the world. The activation of COVID-19 in humanity occurred right now. The pandemic is Covid-19 a direct consequence of the shift of the Earth's magnetic poles. And the bigger the shift, the more waves the pandemic will have. The pandemic Covid-19 reached MOSAIC's unique Arctic scientific expedition in the fall of 2020, while a polar research vessel is locked in Arctic ice near the North Pole. In December 2020, the coronavirus reached the Antarctic continent, which has so far been free of COVID-19.

Each self-respecting newspaper writes something about the "pole shift" and "magnetic anomalies" at least once a month, and when NOAA, that is, the National Oceanic and Atmospheric Administration, hangs up another plate with measurements - so in the press for a couple of weeks just hysteria begins. Therefore, an international expert scientific council on coronavirus is needed, where objective information, statistics, recommendations and means of neutralizing coronavirus could be obtained.

In Japan, a portable device appeared, capable of destroying 99.99 percent of COVID-19 viruses in half a minute. Device represents LED emitter of deep ultraviolet pulses. Deep ultraviolet is highly localized radiation with a very short wavelength, the duration of the pulses of which is measured by femtoseconds (quadrilion fractions of a second). The device LEDs emit deep UV light with a wavelength of 260-280 nanometers (nm) and an optical power of 70 milliwatts.

The author has published several articles on coronavirus [1-7]. This article examines natural patterns and magnetic and mental processes of coronavirus activation and neutralization.

\section{Cellular adaptive immunity}

In conditions of pole change, the significance of cellular adaptive immunity comes to the fore, which is formed by the results of contacts with viruses. It is based on the so-called T-lymphocytes, which give the body's cells a command to produce antibodies when they meet the virus again. As a result, even if no antibodies are found in the blood of the sick, this does not mean that they have no immunity: with a new contact with the virus, Tlymphocytes launch their "production." As a result, people either show no symptoms of the disease at all, or it passes in erased form. Today, virologists explain that $80 \%$ of those infected survive a new coronavirus infection easily, precisely the work of T-cell immunity.

One of the studies conducted in the United States analyzed donor blood samples obtained from 2015 to 2018 - 50\% of them showed T cells by SARS-
CoV-2. A similar study in the Netherlands revealed $20 \%$ of blood samples with $\mathrm{T}$ cells. In Germany, reactive $\mathrm{T}$ cells were found in a third of seronegative SARS-CoV-2 healthy donors (23 out of 68). In Singapore, a team of researchers analyzed blood samples taken from people who had no contact or personal history with SARS or COVID-19; 12 of 26 samples taken before July 2019 showed T cells to the SARS-CoV-2, as did 7 of 11 samples taken from people who were seronegative to the virus. Similar studies with approximately the same data were conducted in the UK and Sweden. Yes, all these studies examined small groups of people, but their results are difficult to ignore.

And now they remembered that something similar happened during the swine flu pandemic in 2009. Many people carried it easily, which was already explained by the presence of reactive $\mathrm{T}$ cells formed as a result of encountering genetically similar influenza viruses. A study conducted during the 2009 outbreak by the U.S. Center for Disease Control and Prevention (CDC) found that $33 \%$ of people over 60 had cross-reactive antibodies to the H1N1 virus.

Today, scientists suggest that cross-immunity to SARS-CoV-2 can be developed not only in those who once had seasonal human coronaviruses, but even in those who met with coronaviruses of some animals.

In theory, outbreaks of infectious diseases follow a certain trajectory. Among the population deprived of immunity, the number of new infections is growing rapidly. At some point in this growth, a bend should occur, and the incidence will begin to fall. In the 1970 s, a theory was born that defined this inflection point as the threshold of collective immunity (HIT) and even a formula for its definition HIT $=1-1 / \mathrm{R} 0$ (R0 is the average number of secondary cases). According to her, experts calculated that under SARSCoV-2, at least $50 \%$ of people need to be ill in order to achieve collective immunity. But there are other, more optimistic calculations - such should be from $10 \%$ to $20 \%$. Scientists at the University of Oxford, for example, believe that when there are people with already existing immunity in the population, as studies of T-lymphocytes can show, the threshold of collective immunity can be reduced to $10 \%$.

Today, for example, everyone is studying the phenomenon of Sweden, where quarantine was abandoned at the beginning of the epidemic - and the number of cases and deaths was off the scale. Today, there in Stockholm, a city of 2 million people, only 50 people were hospitalized with COVID-19. Has collective immunity developed in Sweden? Swedish scientist Buggert conducted a study: studying close relatives of patients with confirmed COVID, he found T-cell responses in those who were seronegative or asymptomatic. While about $60 \%$ of family members produced antibodies, others had $\mathrm{T}$ cell responses.

However, today, speaking of immunity, everyone focused on antibodies. And talk that antibodies to SARS-CoV-2 begin to weaken after only 2-3 months suggests repeated infections. Even doctors are increasingly talking about them. A growing number of evidence from colleagues about reinfections and, worse, that occurred against the background of high antibody titers is encouraging.

With T cells, things may be different: Singaporean scientists, for example, discovered reactive $\mathrm{T}$ cells to SARS-CoV-1 in patients with SARS coronavirus 17 years (!) After infection. The metropolitan doctor, who worked in intensive care in 2003, said that she herself had SARS-CoV-1, which was not believed to be in Russia: Almost all my colleagues were ill we had severe pneumonia, very similar to those that we now see. However, this time, having contracted SARS-CoV-2, I suffered it almost without symptoms, on my legs, although I am at risk. And colleagues who were ill then, now, continuing to work in intensive care, either do not get infected or get sick easily. The viruses SARS-CoV-1 and SARS-CoV-2 are genetically identical by $80 \%$, and obviously we acquired cross immunity. It is estimated that in early 2000, many store sellers, pilots, and airport employees were the first SARS.

At the beginning of the pandemic, the key direction was that we needed antibody data to understand who was infected and how many were protected, "wrote immunologists from Imperial College London. - As we have learned 
more about this complex infection, it is time to recognize that we also need data on $\mathrm{T}$ cells.

So against the background of the recent statement by the representative of WHO that we have not come close to collective immunity, the results of research on cellular immunity are encouraging [8-14].

\section{Magnetic Coronavirus Therapy}

The use of magnets as a physiotherapeutic agent has a long history. Famous doctors of ancient times used the power of magnetic fields to treat various diseases. Since the middle of the 20th century, magnetotherapy has been undergoing a rise, new devices have appeared, while the debate about the effectiveness of the method does not subside. In Russia, the physiotherapeutic school has a great history, and the methods of magnetic therapy are recognized as medical. Treatment with magnetic factors as part of physiotherapy today is one of the links of non-drug and non-surgical rehabilitation.

Studying the effects of magnetic fields on the body and a wide variety of devices in our time have led to a significant expansion of indications for the use of magnetic therapy. Today it is difficult to find a disease in the treatment of which one or another type of magnetotherapy could not be used. Softness of exposure, wide possibilities for personalization and accessibility of the method made magnetotherapy a popular type of treatment and prevention [15-18].

Clinics, sanatoriums and other medical institutions are developing rehabilitation programs after the COVID-19. Mechanisms for recovery from illness are still under study. But it is already clear that magnetic therapy can be safely added to basic medical recommendations - breathing gymnastics, outdoor walks and quality sleep.

All microorganisms, ranging from viruses to fungi and microbes, reach the negative magnetic field. That is, a negative magnetic field is such a great universal antibiotic. When the electric dipole has a negative charge, the magnetic field will also be negative.

The use of a magnetic field to help patients after a severe coronavirus infection began in several subjects of the Russian Federation. Special devices for this previously helped in the treatment of hypertension and diseases of the musculoskeletal system. The pioneers were doctors of the Ivanovo region. They tried to prescribe magnetotherapy to people in whom COVID19 gave complications to the lungs. The wellness effect was evident. Today, this practice has been introduced in some other regions. For example, in Crimea, magnetic therapy is included in the rehabilitation programs of sanatoriums.

Clinical trials have confirmed that the magnetic field has a good effect on the course of treatment of vessels and respiratory organs, spine and joints. The complex provides a medically free effect on the human body with weak and ultra-weak negative magnetic fields: both general and specific - with an eye on a particular organ or system. Metabolism is accelerated, blood oxygen saturation is increased, immunity is improved, cell and tissue regeneration is accelerated. Several hundred sources of magnetic field are controlled from a computer.

The world lives in a state of struggle with a new coronavirus, and hundreds of thousands of patients need restorative treatment. Doctors note that most of those who have undergone coronaviruses even in mild form have symptoms such as shortness of breath, headache, fatigue, depressed mood the so-called postcovid syndrome. Multimag is used to restore patients after COVID-19.

The therapeutic factor of the device is the effect of various magnetic fields. The purpose of the action is to activate the adaptation capabilities of the body and restore metabolic processes. Rostec development can be used in medical institutions, sanatoriums, rehabilitation and fitness centers. "Multimag" is successfully used to strengthen immunity and prevent diseases, including viral infections, which include coronavirus. It treats Multimag with the help of dosed exposure to weak frequency-modulated magnetic fields, and it is possible to affect both the body as a whole and individual organs. At the same time, 400 magnets are involved in the device, and wide possibilities for tuning allow you to choose individual treatment.

The body in the magnetic field behaves like a diamagnet. Diamagnets - have the property of magnetization in the opposite direction of the external field, that is, they have a negative value of magnetic susceptibility, independent of strength. Many organic substances, such as silicon, germanium, spring water and others, contribute to the human body to acquire the properties of a diamagnet. Diamagnet magnetization occurs in the presence of an external field. Magnetic therapy helps the body become a diamagnet and neutralize coronavirus.

The use of low-frequency magnetotherapy in the medical rehabilitation of patients after suffering pneumonia associated with COVID-19 allows improving the general condition, lung function, increasing physical activity and contributing to the restoration of activity in everyday life.

\section{Mental protection against coronavirus}

In an environment with positive mental energy, pathogenic organisms do not develop: bacteria and viruses, including coronavirus.

Scientists have identified a mental field around the brain [19]. The mental field ensures the normal course of all neurophysiological processes. It is determined that this mental field is highly energetic on special carriers, which are epiphysis crystals. They make it possible to keep a huge energy information volume in the protein body.

In the situation with coronavirus, when the problem must be solved immediately, the active generation of mental energy of enormous strength begins. And then the psychoenergetic process of exposure to coronavirus is performed. Not many can consciously manage mental energy. Psychological protection is associated with positive content of thoughts, feelings and behavior.

From a spiritual point of view, coronavirus is a cleaner. The level of moral, ethical and spiritual standards is low in large cities. Humans do not keep God's covenants. The world lives in evil. It makes spiritual sense that the widespread disease with coronavirus occurred on the eve of Lent and understanding of sins before the celebration of the nativity of Christ. We must understand that this is a punishment for sins. We must understand and understand this well, and from this we must proceed in our lives [20-21]. And always ask God for forgiveness - both for himself and for peace. The Lord will pardon and protect, if we really all realize sinfulness, we will obediently strive to live according to the covenants of God, then the pandemic will end.

Megacities are an urban environment with a concentration of low spiritual energies. Coranavirus causes people to cleanse themselves mentally and increase positive mental energy. The virus does not affect those who constantly seek to reveal their essence. Coronavirus has energy, information, and several molecules. It is at the level of energy frequencies and functions on other vibrations than a spiritual person with positive mental energy.

\section{Conclusion}

Long-term studies of viral mass diseases indicate the realizing role of natural processes and the controlling role of spiritual processes in the international phenomenon of pandemics. The results of the studies set out in the article and publications. confirm this. The controlling substance reveals the spiritual level of society. In accordance with the spiritual level of society and the ecological state of the environment, it launches natural processes and mechanisms according to spiritual laws to cleanse people. Currently, another natural process in the form of coronavirus infection has been launched to cleanse humanity. It is already becoming seasonal in order for peoples to realize the unrighteous destructive activities of life, to correct and improve it by observing spiritual, hygienic, sanitary and environmental standards for the benefit of humanity and nature. 


\section{References}

[1] Evgeniy Bryndin, Irina Bryndina. How the situation with the virus was COVID-19 in South Korea. Journal of Medical Case Reports and Reviews 3:4. 2020. Pages: 643-646.

[2] Evgeniy Bryndin. Management Experience in Fighting with COVID-19 and Other Aspects of Counteraction. American Journal of Management Science and Engineering. Volume 5, Issue 2, 2020. Pages: 19-23.

[3] Evgeniy Bryndin, Irina Bryndina. Countries have Accumulated Experience in Combating COVID 19 to Build System of Effective Neutralization. Clinical Case Reports: Open Access,

Volume 3 Issue 3, 2020. P. 1-7.

[4] Evgeniy Bryndin. Vibration approach to coronavirus detection and neutralization COVID-19. American Journal of Laboratory Medicine, Volume 5, Issue 4, 2020. pp. 113-117.

[5] Evgeniy Bryndin. Resonance approach of detection and neutralization COVID-19. Japan Journal of Medical Science, Volume 1, Issue 2, 2020. pp.11-15.

[6] Evgeniy Bryndin. Implementation of International Telemedicine network with Rapid Coronavirus Registration by Resonant Technology to Neutralize the Pandemic. Computational Biology and Bioinformatics. Vol. 8, Issue 2, 2020, pp.29-35.

[7] Evgeny Bryndin. Natural Mechanisms and Methods of Protection Against Coronavirus COVID-19. Journal of Medical Research Health and Sciences, Volume 4: Issue 2. 2021. pp. 1182-1186.

[8] Evgeniy Bryndin. Self Healing of Healthy Condition at Cellular Level. Medical Case Reports and Reviews, Volume 3, London. 2020. Pages: 1-4. doi: 10.15761/MCRR.1000142

[9] Sawsan S. Alamri, Khalid A. Alluhaybi, Rowa Alhabbab, Mohammad Basabrain. Synthetic SARS-CoV-2 Spike-Based DNA Vaccine Elicits Robust and Long-Lasting Th1 Humoral and Cellular Immunity in Mice. Frontiers in Microbiology, Volume 12, 2021.

[10] Andrea M. Spiri, Jonathan E. Fogle, Felicitas S. Boretti, Imogen Herbert. Modified-Live Feline Calicivirus Vaccination Elicits Cellular Immunity against a Current Feline Calicivirus Field Strain in an Experimental Feline Challenge Study. Viruses 2021, 13, 1736. https://doi.org/10.3390/v13091736

[11] Lisa R. Volpatti, Rachel P. Wallace, Shijie Cao, Michal M. Raczy, Ruyi Wang. Polymersomes Decorated with the SARS-CoV-2 Spike Protein Receptor-Binding Domain Elicit Robust Humoral and Cellular Immunity. ACS Cent. Sci. 2021, 7, 1368-1380

[12] Cheng-Wei Chang, Hongwei Liu. A Glimpse into the Diverse Cellular Immunity against SARS-CoV-2. Vaccines 2021, 9, 827. https://doi.org/10.3390/vaccines 9080827
[13] Copley HC, Gragert L, Leach AR and Kosmoliaptsis V (2021) Influence of HLA Class II Polymorphism on Predicted Cellular Immunity Against SARS-CoV-2 at the Population and Individual Level. Front. Immunol. 12:669357. doi: 10.3389/fimmu.2021.669357 [14] Athina Kilpelainen, Bibiana Quirant-Sánchez, Oscar BlanchLombarte, Eva Martinez Caceres. Highly functional Cellular Immunity in SARS-CoV-2 Non-Seroconvertors is associated with immune protection. Preprint . May 2021. DOI: 10.1101/2021.05.04.438781

[15] Markov M., Nindl G., Hazlewood C. and Cuppen J. Interactions Between Electromagnetic Fields and Immune System: Possible Mechanism for Pain Control. In: S. Ayrapetyan and M. Markov (eds.), The Mechanisms of Biological Effects of Extra High Power Pulses, NATO Advance Research Workshop series, Springer, 2006

[16] Slotema, C. W.; Dirk Blom, J.; Hoek, H. W.; Sommer, I. E. (2010). "Should we expand the toolbox of psychiatric treatment methods to include Repetitive Transcranial Magnetic Stimulation (rTMS)? A meta-analysis of the efficacy of rTMS in psychiatric disorders". Journal of Clinical Psychiatry. 71 (7): 873-84. doi:10.4088/jcp.08m04872gre. PMID 20361902.

[17] Teresa Paolucci, Letizia Pezzi, Antonello Marco Centra, Niki Giannandrea, Rosa Grazia Bellomo, Raoul Saggini, Electromagnetic Field Therapy: A Rehabilitative Perspective in the Management of Musculoskeletal Pain - A Systematic Review. Journal of Pain Research 2020:13, pp. 1385-1400

[18] Alsayed Abd Elhameed Shanb, Enas Fawzy Youssef. The Efficacy of Adding Electromagnetic Therapy or Laser Therapy to Medications in Patients With Diabetic Peripheral Neuropathy. Journal of Lasers in Medical Sciences · January 2020. DOI: 10.15171/jlms.2020.05

[19] Evgeny Bryndin. Professional Training of Intellectual Disabled Person by Holographic Image of Competent Healthy Specialist. International Journal of Psychological and Brain Sciences. Volume 6, Issue 3, 2021. pp. 44-51.

[20] Evgeny Bryndin, Human Evangeliyezation and Diaconic Service of Believers to Neighbors in Unity of Liberty According Law of Love. International Journal of Research in Humanities and Social Studies, 7(4), 2020, pp. 1-8.

[21] Evgeny Bryndin. Spiritual Foundation of Being and the Source of the Right Life. Scholars Journal of Arts, Humanities and Social Sciences | Published by SAS Publishers, India. Volume-9 - Issue-09. 2021. pp. 367-370. 
(C) (7) This work is licensed under Creative Commons Attribution 4.0 License

To Submit Your Article Click Here: Submit Manuscript

DOI: $10.31579 / 2692-9392 / 087$
Ready to submit your research? Choose Auctores and benefit from:

* fast, convenient online submission

* rigorous peer review by experienced research in your field

* rapid publication on acceptance

* authors retain copyrights

* unique DOI for all articles

* immediate, unrestricted online access

At Auctores, research is always in progress.

Learn more www.auctoresonline.org/journals/archives-of-medical-casereports-and-case-study 